\title{
Gerontological Counseling Training: The State of the Art
}

\author{
JANE E. MYERS
}

\begin{abstract}
This study reveals that 37\% of counselor education departments nationwide offer coursework to rain counselors to work with older people, a significant increase since 1975.
\end{abstract}

In 1975, Richard Blake defined older persons as "the forgotten and ignored of APGA." His statement was supported by the paucity of articles in the counseling literature dealing with older people, as well as a general lack of interest among counselors and counselor educators. The response to his challenge that we direct our attention to this unserved population is still burgeoning. In this article, the impact of increasing interest in counseling older persons is explored from the perspective of training opportunities available for gerontological counselors.

The results of a 1975 study by Salisbury revealed that only 18 of 304 or $6 \%$ of all counselor education programs offered even an elective course in aging, and not one had a required course in this area. The present study, conducted in 1981, is essentially a replication of Salisbury's research with additional questions asked to determine, as accurately as possible, the current status of training opportunities for gerontological counselors.

\section{BACKGROUND INFORMATION: CURRICULUM DESIGN}

The development of new coursework in any area depends greatly, on the availability of curriculum resources. In 1975, little information was available to assist counselor educators in the design and conduct of gerontological counseling courses.

APGA responded to this need in 1977 by entering into a one-year cooperative agreement with the U.S. Administration on Aging (AOA) to develop curriculum materials for graduatelevel training of gerontological counselors. The Special Training Project on Counseling the Aged produced two books and a media presentation. Counseling the Aged: A Training Syllabus for Educators (Ganikos, 1979) contains an extensive amount of information to assist educators in teaching about the counseling related concerns of older people. A Handbook for Conducting Workshops on the Counseling Needs of Older People (Ganikos, Grady, Olson, Blake, Fitzgerald \& Lawrence, 1979) is a monograph to assist in the preparation of workshops ranging from one hour to one day in length. The slide-tape presentation, Hey, Don't Pass $M e B y$, depicts the potential role of counseling in the lives of older people.

APGA and AoA followed the first successful aging project with the National Project on Counseling Older People, a two-year agreement directed toward the communication skills training needs of service providers to older persons. In contrast to their first project, which was aimed at the preparation of professional counselors, this project focused on training per- sons at the peer and paraprofessional levels. The project had a dual purpose, the first of which was to stimulate the development of a nationwide network of training programs for service providers, combining the eftorts of counselor educators and persons working in the aging services network. The second purpose, the development of curriculum materials to assist in accomplishing the former goal, resulted in a three volume set of training materials. Counseling Older Persons, Volume I: Guidelines for a Team Approach to Training (Myers, FinnertyFried, \& Graves, 1981) presents a blueprint for developing the kinds of training programs fostered by the project and includes a directory of project participants and training teams to serve as resources throughout the country. Counseling Older Persons, Volume II: Basic Helping Skills for Service Providers (Myers \& Ganikos, 1981) is a text for use in training paraprofessional and peer counselors and for training service providers to older people in basic helping skills. Counseling Older Persons, Volume III: A Trainer's Manual for Basic Helping Skills (Myers, 1981) provides supplemental information and activities to augment the trainer's repertoire of resources for teaching basic communication skills.

Since 1975, APGA has produced several special issues of its journals dealing with various aspects of counseling for older persons:

Counseling over the life span, 1976 special issue of the Personnel and Guidance Journal, edited by Sinick.

Work/Life counseling for older people, 1980 special issue of the Journal of Employment Counseling, edited by Ganikos.

Counseling the elderly, $\mathrm{I}$, II and III, three 1980 special issues of Counseling and Values, edited by Fulvino and Colangelo.

Children and older people, 1982 special issue of the School Counselor, edited by Capuzzi.

Aging and assessment: The state o. the art, 1982 special issue of Measurement and Evaluation in Güidance, edited by Myers and Rimmer.

A special issue of the ACES journal has also been proposed as well as a special issue of the Rehabilitation Counseling Bulletin. An increasing number of articles dealing with older persons

Jane E. Myers, Ph.D.,C.R.C. is Assistant Professor of Guidance and Counseling and Director or Rehabilitation Counselor Education at Ohio University in Athens. The author wishes to express sincere appreciation to Pamela Finnerty-Fried, as well as to Nancy Freiert, Howard Weiner, and Claudius Oni for assistance with data collation and analysis. 
is appearing in the professional literature in counseling, a trend which is expected to continue.

Several books directed to counselors and counselor educators are also available, and include the following: Counseling Older Persons: Careers, Retirement and Dying (Sinick, 1975), Counseling for the Growing Years: 65 and Over (Pulvino \& Colangelo, 1980), Counseling the Elderly: for Professional Helpers Who Work with the Aged (Landreth \& Berg, 1981), and Counseling Elders and Their Families (Herr \& Weakland, 1979).

The point to be made is that lack of resources, both in curriculum and knowledgeable individuals, is no longer a barrier to the development of gerontological counseling course work. Institutions and individuals who want to develop courses in this area have adequate assistance to do so. The question remaining to be answered is that of how many institutions actually have responded to the growing need for training gerontological counselors.

\section{METHODOLOGY}

Based on Salisbury's (1975) research, a survey form was designed to elicit a variety of information concerning training opportunities in gerontological counseling. Following review by the Executive Staff of APGA, the questionnaire (as revised) was mailed to 484 counselor education departments (or counseling psychology) identified using the Counselor Education Directory (Hollis \& Wantz, 1981). A cover memo explained the twofold purpose of the survey: first, to determine the numbers, locations, and extent of gerontological counseling training programs throughout the country and second, to develop a directory of such programs to be made available nationally.

The first mailing, in late spring 1981, yielded a low (31\%) rate of return. Considering possible interference due to quarter' semester breaks, a second mailing was sent in the summer only to those institutions which had not responded to the first mailing. This second mailing raised the overall rate of return to $50 \%$. A third mailing of the questionnaire to institutions that had not responded occurred in the fall of 1981, as an added assurance that those counselor education programs offering coursework in aging had adequate opportunities to respond to the survey and have their programs included in the planned directory. The resulting sample included $65 \%$ of the departments surveyed. The questionnaire format and responses did not differ on the second and third mailings, and the original cover memo was included for each. A brief additional memo, explaining that this was a second or third mailing, was included to encourage questionnaire returns.

\section{DATA ANALYSES}

The data generated by the survey were analyzed using standard SPSS computer programs, with the major statistical analyses being frequency counts for the various survey items. In addition, it was necessary to classify the specific course information due to great variability in course titles and content. Four distinct categories of courses emerged from a review of the data, and each course listed by the responding departments was assigned by trained raters to one of the following four classifications.

Level 1. Gerontological counseling course taught in counselor education department. These courses had titles specifically reflecting gerontological counseling as the primary content area; for example "Counseling the Aged," "Counseling Older Persons," "Retirement Counseling," "Gerontological Counseling."

Level 2. Course offerings in counselor education departments dealing primarily with content relating to adult development and aging; for example, "Counseling Adults," "Adult Development and Aging."

Level 3. Course offerings in counselor education departments not specifically related to aging or gerontological counseling, but having one or more units within the course focused on older persons; for example, a unit on coping with elderly parents in a family counseling course; a unit on retirement in a career and life planning course.

Level 4 . Course offerings in aging related areas in university departments other than counselor education, primarily as part of a campus certificate-in-gerontology program, which are taken by gerontological counseling students and which are related to counseling needs of older persons, for example, "Adult/ Human Development"; "Mental Health and Aging."

\section{RESULTS}

After three mailings, 306 of the 474 counselor education departments, or $65 \%$, responded to the survey. A total of 114 , or $37 \%$ of those responding reported that they currently offer courses to train counselors to work with adults and older persons. Further, 81 of the respondents indicated an intent to develop additional course offerings in this area of study.

$A$ list of university programs that offer courses to train gerontological counselors, arranged according to ACES region and state, is currently being developed as a directory for dissemination through APGA. This listing is not duplicated here, for several important reasons. First, the data gathered reflect training opportunities at a particular point in time, and therefore any listing at another point in time would tend to be inaccurate. Second, a listing of programs with an indication of numbers of courses in each level would raise more questions concerning the nature of specific courses than it answered. Therefore, the results are reported only in terms of total numbers and more specific and detailed information will be included in the directory.

A total of 54 universities reported Level 1 course offerings, defined as gerontological counseling courses taught in a counselor education department. Fifty-seven programs reported having level 2 courses, defined as courses having content related to adult development and aging. Forty-one departments reported offering units on aging within other counselor education courses, and 28 level 4 courses were listed. These indicated course offerings in aging-related areas in other departments of the university.

Forty-two of the programs that responded offer a degree program or specialization in gerontological counseling at the Master's level. Six of them offer a specialization at the Ed.S. or educational specialist level and ten offer a specialization at the doctoral level. (Only one school reported offering a specialization at all three levels.) An additional 12 departments reported an intent to develop a degree program or specialization.

The number of programs offering gerontological counseling training in each of the ACES Regions as compared to the total number of programs surveyed in each region, is as follows: Southern-36 of 153 programs (24\%); North Central-33 of 127 programs (26\%); North Atlantic-28 of 104 programs (27\%); Western-14 of 66 programs (21\%); and Rocky Mountain-3 of 24 programs (13\%).

Among those universities that do not currently offer course work to train counselors to work with older persons, 80 indicated an interest in developing such offerings. Twenty-one of them also indicated a desire to develop a degree program or specialization. In response to a sub-part of this question, 12 stated that this specialization would be at the Master's level, three at the Ed.S. level and two wanted to develop a specialization at the doctoral level.

The majority of departments ( $N=114$ for this question only) indicated that only one faculty member taught gerontological counseling courses $(65$, or $57 \%)$. Thirty departments $(26 \%)$ reported having two faculty members teaching in this area, 14 $(12 \%)$ reported having three or more faculty, and $5(4 \%)$ indicated that 4 or more faculty taught in this area. 
When questioned concerning theses and dissertations related to aging, the following figures were reported by the departments: 30 completed theses, 31 completed dissertations, 16 theses currently in process and 23 dissertations underway. (It should be noted that most or all of these projects may be complete at the time of this writing, and more may be projected to be in progress.)

Practicum opportunities in settings where students work directly with older people were available through 26 departments (8.5\% of respondents), while 188 reported that such opportunities were not available. The percentages of students completing practica at these sites, where available, were small. In fact, over $80 \%$ of respondents indicated such placements for less than $5 \%$ of their total student enrollment, while more than $90 \%$ (cumulative percentage) indicated that less than $10 \%$ of students completed practica in settings where they worked with older people.

Sixty-six programs reported having a clinic or counseling center serving their community, and most indicated that fewer than $5 \%$ of the clients seen in the clinic were elderly.

\section{DISCUSSION}

In interpreting the data for this study, some potential limitations should be mentioned. First, due to the dynamic nature of university departments and to changing attempts to meet identified community needs, existing courses are often redefined and new courses developed. The present study describes the "state of the art" at one point in time, and this surely will be revised by the time this appears in print.

Second, in requesting information on existing courses, the author may have erred in the direction of being too open-ended in the design of questions. Although it is impossible to verify such a concern at this time, the possibility must be considered that schools with similar course work responded differently in terms of course levels described. Thus, some departments having level 3 and level 4 courses may have failed to list them.

Third, because the size of each department and overall number of course offerings and students was not included in the study, it is not possible to make inferences about the relationship of department size to the availability of gerontological counseling course work.

Of primary importance is the fact that $37 \%$ of the responding programs offer courses to train counselors to work with older people. This is a marked increase over the $6 \%$ found in Salisbury's (1975) research and is indicative of increasing attempts within the profession to train counselors to work with the large and growing population of older people. The actual number may be larger, based on responses from the 178 programs that did not respond to the survey; however, the fact that a directory was to be produced suggests that nonrespondents probably did not have such courses. Otherwise, they might have chosen to be included in a national directory. The numbers of gerontological counseling training programs will undoubtedly increase as the 80 universities that indicated an interest but no courses as yet proceed in the development of course work in this area.

A review of the results reveals that, although training programs exist in each of the ACES regions, the heaviest concentration, in sheer numbers, occurs in the Southern region, followed by the North Atlantic and North Central areas. A variety of reasons may be postulated for this finding. First, much of the leadership of APGA in the area of gerontological counseling resides in these areas. These individuals, through their professional activities and involvements, may have stimulated additional interest in their geographic areas. They also may have served as resource people to others within their respective regions to assist in the development of programs. Hopefully, as they continue to do so, the numbers of programs in all regions will expand. It is also interesting to note that, apart from the total numbers of programs the proportion of departments offering gerontological counseling course work is virtually identical for the Southern, North Central, and North Atlantic regions.

In addition to course work offerings, the development of gerontology specializations within counselor education departments is encouraging. At this point in time, students desirous of such special emphases may elect to pursue a masters degree at a large number of universities. The availability of a doctoral specialization in only ten programs perhaps reflects the smaller need for persons trained at the doctoral level as compared to the M.S. level. The ten programs reporting doctoral specializations increasingly may be recognized as leaders in research and preparation of gerontological counselors. As increasing numbers of theses and dissertations are completed around the country, even more departments are coming to be recognized for contributions to our knowledge base in this area. It is expected that as more faculty become involved and interested, additional students may pursue course work and research in gerontological counseling.

An important need, shown by the results of this study, is for the development of practica and internship sites where students may apply their specialized knowledge to work with older people. Because social workers traditionally have served the older population, counselors may expect to have to conduct outreach and awareness activities if community agencies are to be made aware of the valuable services we may offer for older people. One way to increase this awareness is to increase the extent of services to older people in university clinics serving the community. (This also may serve to make students more aware of the needs and potential for growth of older individuals.) Another way is to increase the number of practica and internship placements at sites serving older people, such as senior centers, nursing homes, and retirement housing programs. These placements also serve as effective sources of job leads for counseling graduates.

\section{CONCLUSION}

In the past seven years, there has been a substantial increase in the number of counselor education programs offering course work to train gerontological counselors. The many events that have contributed to this expansion include the impact of two APGA aging projects, the development by APGA and others of a variety of curriculum materials and research reports, and numbers of presentations at professional meetings. These and many other activities have served to increase awareness within the profession of the needs and potential of our older population. Perhaps further research will reveal why more programs do not offer course work in this area, and what types of activities we may engage in to stimulate additional training opportunities. Although we have a long way to go, it is encouraging to learn that we, as a profession, are making consistent, rapid, and significant growth toward meeting the need for training counselors to work with older people.

\section{REFERENCES}

Ganikos, M. L. Counseling the aged: A training syllabus for educators. Falls Church, Va.: American Personnel and Guidance Assocation, 1979. Ganikos, M. L. Grady', K., Olson, J., Blake, B., Fitzgerald, P., \& Lawrence, P. A handbook for conducting workshops on the counseling needs of older people. Falls Church, Va.: American Personnel and Guidance Association, 1979.

Herr, J. J., \& Weakland, J. H. Counseling elders and their families. New York: Springer, 1979.

Hollis, W. J., \& Wantz, R. (eds.). Counselor education directory, 1981. Muncie, Indiana: Accelerated Development, 1981.

Landreth, G. L., \& Berg, R. C. Counseling the elderly: For professional helpers who work with the aged. St. Louis: C. C. Thomas, 1982.

Myers, J. E. Counseling older persons, Volume III: A trainer's manual for basic helping skills. Falls Church, Va: American Personnel and Guidance Association, 1981. 
Myers, J. E., Finnerty-Fried, P., \& Graves, C. Counseling older persons, Volume I: Guidelines for a team approach to training. Falls Church, Va: American Personnel and Guidance Association, 1981.

Myers, J. E., \& Ganikos, M. L. Counseling older persons, Volume II: Basic helping skills for service providers. Falls Church, Va: American Personnel and Guidance Association, 1981.
Pulvino, C. J., \& Colangelo, N. (eds.). Counseling for the growing years: 65 and over. Minneapolis: Educational Media Corporation, 1980.

Salisbury, H. Counseling the elderly: A neglected area in counselor education and supervison. Counselor Education and Supervision, 1975, 14 (3), 237-38.

Sinick, D. Counseling older persons: Careers, retirement and dying. Washington, D.C. American Psychological Association, 1975.

\title{
Reactive Depression and Chronic Illness: Counseling Patients and Their Families
}

\author{
FREDRICA G. HALLIGAN
}

Major theories and research findings are presented with specific suggestions for counseling approaches to reduce prevalence and impact of depression that often accompanies physical illness.

In human terms depression accounts for a great deal of personal and domestic suffering. Depression is defined as an affect state that can vary in intensity and that may be based on either a relatively accurate appraisal of life circumstances or on serious distortions of reality (Blatt, 1974). Depression is not uncommon in medical patients. Steward (1965) found $20 \%$ of patients to be depressed following the onset of a fatal or disabling disease while Schwab and his associates found various forms of depressive syndrome to run $28-30 \%$ in general medical population (Schwab, Bialow, Brown, \& Holzer, 1967). The effects of depression undoubtedly worsen the illness by slowing down the metabolic functioning and thus prolong the process of adaptation and healing.

Depression is not a simple state. Biochemical and psychogenic factors may interact in a manner that has become an area of considerable research interest (Depue, 1979). Although some symptoms may be similar to the "blue mood" that affects all individuals in times of physical depletion, depressions constitute a highly complex group of disorders that are not yet fully understood. There is convincing evidence of inherited predisposition for certain forms of endogenous depression (Gershon, Bunney, Leekman, Van Eerdewegh, \& De Bauche, 1976; Rosenthal, 1969). In these forms of depression biochemical factors seem to be primary (Arieti \& Bemporad, 1978, Depue, 1979, Groves \& Schlesinger, 1979). The American Psychiatric Association (1980) delineates the major endogenous depressions as unipolar and bipolar (i.e., manic-depressive), while minor affective disorders may be cyclothymic (similar to bipolar but less severe or shorter duration), or dysthymic (chronic disturbance of mood showing either depression or loss of interest and pleasure in ordinary activities.) It is important to note that, while the major depressions may range to psychotic or suicidal proportions, there is also frequently the occurence of remissions where the individual seems to be both behaviorally and affectively normal.

Medical patients may present a dual set of symptoms: those of both physical illness and major depressive disorder. As- sessment of such patients should include evaluation of the possibility of endogenous depression with biochemical factors for which drug treatment may be beneficial. Frequently, however, what patients with medical illnesses experience is reactive depression. In contrast to endogenous depression, which can occur at any time and may be due to an interaction of inherited and environmental factors from early childhood, reactive depression is more situation specific. Reactive depression can be, for example, an intensification of grief reaction, or it may be the individual's response to bodily deterioration. Whereas endogenous depression often responds to biochemical intervention, reactive depression is thought to be psychogenic in origin and more responsive to interpersonal forms of therapy (Arieti \& Bemporad, 1978; Depue, 1979). Consider, for example, the following case:

\begin{abstract}
Annette is a petite woman in her late twenties. She was married in her teens and has two children. She has had multiple sclerosis (MS) for the past eight years and has borne up courageously, even cheerfully, to the stresses of a divorce and gradual weakening of her legs which recently necessitated her use of a wheelchair. She is attractive and fastidious about her appearance. In her counseling session she sometimes cries uncontrollably as the impact of her physical deterioration gradually wears away her defenses. The effort to comb her hair or to put on a pair of slacks is exhausting. In group therapy she listened for many months while other patients talked about the degeneration of bowel and bladder incontinence. Now she knows that she too is headed in that direction, and the knowledge is seemingly more than she can bear. Her need for support and counseling is great while she deals with the impact of this physical transition that will lower her level of effective functioning.
\end{abstract}

MS is a degenerative disease and its victims, like other patients with physical infirmaties, must not be left to suffer alone. In

Fredrica G. Halligan is staff psychotherapist, Albert Einstein College of Medicine, New York. 